\title{
NIST and the CEIDP—Working Together to Advance Technology
}

\author{
R. E. Hebner \\ The University of Texas at Austin, Austin, TX, USA
}

\begin{abstract}
The technology underpinning the electrification and the growth of telecommunications in the United States stimulated a long-term relationship between the Conference on Electrical Insulation and Dielectric Phenomena and the U. S. National Institute of Standards and Technology. This interaction, based on common technology, helped the National Institute of Standards and Technology with quality control, dissemination activities, and program planning. It helped the Conference in the development of technical thrusts and in staffing its activities.
\end{abstract}

\section{Introduction}

In March of 2001, the National Institute of Standards and Technology (NIST) marked the 100th anniversary of its founding as the national metrology institute of the United States. At its founding, it was modeled on already successful institutions in Germany, England, Austria, Russia, and France [1]. Subsequently most nations involved in significant international commerce have established similar institutions.

Thirty years after the founding of NIST, the first annual meeting of the Conference on Electrical Insulation and Dielectric Phenomena (CEIDP) was held. This conference has provided a forum in which the latest research, developments, and formulations concerning electrical insulation and dielectrics are discussed. Through much of its early history, the CEIDP was an activity of the National Academy of Sciences in the United States. It also tended to be held in locations convenient for staff from General Electric Research Laboratories, Westinghouse Research Laboratories, and the Bell Laboratories to attend. This was expected as the telecommunications industries and the electricity supply industries were significant industries of the time. They were also key industries advancing the understanding of dielectrics and electrical insulation.

Both NIST and the CEIDP have evolved significantly throughout their lives. During much of the time of their joint existence, however, the two organizations have closely cooperated. The varying reasons for this cooperation may provide some guidance for the leadership of the CEIDP and for companies and organizations in their dealings with professional societies and conferences.

\section{NIST Use of CEIDP}

The act to establish the National Bureau of Standards (PL 177-56) listed the following functions for the organization:

1. Custody of standards.

2. Comparison of the standards used in scientific investigations, engineering, manufacturing, commerce, and educational institutions with the standards adopted or recognized by the government.

3. Construction of standards.

4. Testing and calibration of standard measuring apparatus.

5. Solution of problems that arise in connection with standards.

6. Determination of physical constants and properties of materials, when such data are of great importance to scientific and manufacturing interests and are not to be obtained of sufficient accuracy elsewhere.

Probably the largest change to this mission occurred in 1988 when the Omnibus Trade and Competitiveness Act was adopted. This act changed the name of the National Bureau of Standards to the National Institute of Standards and Technology and added three more functions to the functions listed above. These were:

1. The Advanced Technology Program - A program to partner with the private sector to develop broadly beneficial technologies.

2. The Manufacturing Extension Partnership - A program that provides technical and business assistance to smaller manufacturers.

3. The Baldrige National Quality Program A program that promotes and recognizes organizational performance excellence.

While there would have undoubtedly been some 
interaction between NIST and the CEIDP just due to technical interest of the staff, it is likely that the longterm relationship persisted because of items \#2 and \#6 in the original functions of NIST. These gave NIST the responsibility to understand the operational standards used by the various parties in the U.S. as well as to provide physical constants and data that were not otherwise available.

As a mission, NIST staff and management recognized this is clearly open ended. The number of possible standards, constants, and physical data possibly of interest is nearly unbounded. Programmatic priorities were typically set to try to anticipate and meet key industrial need. The prediction of future important technologies is an inexact art, but history shows that they tend to align with the key industries of the era.

As mentioned above, the electrification of the U.S. and the growth of telecommunications have been among the industrial drivers of the U.S. economy for the past century. Because the CEIDP was striving to illuminate the evolving important technical problems in dielectrics and electric insulation, technologies important to these industries, there was a convergence of interest between NIST and the CEIDP.

\section{CEIDP Use of NIST}

The role of the CEIDP, as contrasted to that of NIST, is not codified into law. Rather it has been largely the result of the evolving vision of the people involved in its organization. Prior to the 1980's a significant feature of the Conference is that is was an opportunity for the development of a collegial spirit among researchers in related fields. The conference was generally held in a remote self-contained location where all attendees listened to each talk together and shared each meal at relatively large communal tables.

This culture provided a significant rudder as the CEIDP made the significant transition from sponsorship of the U.S. National Academy of Sciences to the IEEE, a transnational technical organization. The transition, the CEIDP is no longer the collegial U.S.-centered organization that it had been. It is now much more strongly influenced by transnational issues.

In both incarnations, however, the conference used NIST staff. For more than thirty consecutive years, there has been one or more technical presentations from NIST at the conference. NIST hosted a meeting of the conference. A NIST staff member served as the conference Chairman and another as Digest chair. A number of NIST staff members have served on the Conference Board, on the Program Committee, and as session chairs. Today, the website used by this conference is hosted on a NIST computer.

\section{Important Areas of Technology}

Technology sustained the NIST-CEIDP relationship. There are specific areas of technology that were important to the NIST mission. In some of these areas, the organizers of the CEIDP worked to attract the world's best and most recent work to the conference. Those areas tended to become examples of effective linkages between the organizations. These areas in which this occurred included the following topics.

Dielectric properties of polymeric materials: The 1960 's to the 1980's were probably the peak of the development of polymeric insulation for cable. This era saw the installation of such cables for transAtlantic telephone communication as well as for high voltage, high power cabling. While the industry was perfecting these applications, NIST staff were developing supporting measurement capability and reporting it at the CEIDP. The most significant NIST work of this period was probably that focused on the measurement of dielectric properties over the subhertz to megahertz range of frequencies.

Measurement of space charge: An important capability that was introduced to the field in the last twenty years of the last century was the ability to measure space charge distributions. This was an era that showed significant advancement in space charge measurements in liquids, in solids, and at interfaces. The advance was made possible by advances in electrical and optical measurement sensitivity. The improved optical sensitivity permitted novel uses of electro-optical measurement techniques. The improved electrical measurement capability led to measurement techniques using acoustical or thermal probing. The CEIDP was the conference of choice for presenting advances in this area and NIST used the conference as an effective means to evaluate and improve its contributions.

Streamers in Liquids: Streamers in liquids had been very poorly understood as the techniques to 
measure them were not sufficient to elucidate properties. Attempts were made to develop an understanding of the process by comparing photographs of different streamers during different phases of their development. The introduction of highly sensitive framing cameras and advanced techniques to shutter light stimulated a number of laboratories around the world to make rapid advances in understanding streamer propagation in the late 1980's and 1990's. The intense interest generated at the CEIDP was a pacing function for this research. Most groups planned their work so that they had something significant to present at the annual meeting. This was an area to which the NIST program made a few important contributions.

Physical Chemistry of Discharges: At the same time the understanding of streamer behavior was advancing, the community was developing the tools and data needed to predict the chemical byproducts produced by discharges either in a gas or a liquid. The data were particularly significant in assessing health and environmental effects of the use of chlorinated biphenyls or sulfur hexafluride to insulate high voltage power apparatus. NIST staff helped by providing some of the rate constants needed in the chemical kinetics models and with selected applications of the models. These topics were challenging for the Conference as the technical results had significant economic consequences. A conference dedicated to open communication of the latest results has difficulty when potential legal liability limits technical discussion.

\section{Benefits}

A long-term relationship between a conference and a technical organization does not persist unless it is mutually beneficial. A clearer understanding of those benefits may help the CEIDP leadership guide the evolution of the Conference. Similarly, it may assist other organizations in articulating the value of a strategic relationship with the CEIDP. For NIST, the benefits can be considered in two general categories.

The first, and generally the better recognized, is for the individual researcher. For the individual researcher, the CEIDP provides an environment to report the latest results, to meet with the leaders in the field, to get ideas for future work, to get insightful comments on current work, to build collaborative programs, and to learn about related advances in the field. Many NIST staff members took advantage of this environment.

For NIST as an institution, however, the rewards are related but somewhat different. One key institutional benefit was technical quality control. NIST management could and did monitor how work was received at the CEIDP. If a body of work was leading, or in the mainstream of, a growing series of papers, it was likely the work was both relevant and of good quality. Other reactions from the community required that the work be re-examined.

Another key benefit was that the CEIDP provided a cost-effective means to distribute the results of NIST's work. The measurement technology and physical data NIST develops must be used for the NIST programs to be effective. A very effective means to stimulate diffusion is to put the information in the hands of the technology leaders. This is precisely a benefit that the CEIDP provided NIST.

A third institutional benefit to NIST was that the CEIDP provided insight and advice needed for program planning. Many of the industrial advisors to NIST were selected because of their involvement with the CEIDP. At the CEIDP, NIST staff could judge who had a vision and breadth of knowledge that would be useful in program planning and assessment.

It is likely that the key benefit to the CEIDP was in the staff time to carry on the work of the Conference. NIST staff played both supporting and leadership roles in the Conference. It is important to emphasize that CEIDP involvement was generally career enhancing for NIST staff, because of the benefits NIST gained from the conference.

A second important benefit to the CEIDP has been ideas for technical emphasis. NIST is a large organization with international connection and programs at the leading edge of many technologies. The NIST staff brought this perspective to the table as programs were being developed. The NIST perspective added seasoning to the stew that, year after year, was the technical program of the CEIDP.

\section{Acknowledgements}

The author would like to acknowledge that Tom Dakin, Harry Sharbaugh, and Eric Forster, each in very different ways, helped me to understand why both high quality technical work and conference involvement are important if a program is to be successful. 


\section{References}

[1] R. C. Cochrane, Measures for Progress, New York, NY, USA: Arno Press, 1976.

Author address: Robert Hebner, The University of

Texas at Austin, Mail Stop R7000, Austin, TX

78712, Email: r.hebner@mail.utexas.edu. 